Bouncing back from Workplace Stress: From HRD's Individual Employee's Developmental Focus to Multi-facetted Collective Workforce Resilience Intervention
Advances in Developing Human Resources

(C) The Author(s) 2020 Article reuse guidelines: sagepub.com/journals-permissions DOI: | 0.1 | 77/|I52342232094623 | journals.sagepub.com/home/adh

John Mendy'

\begin{abstract}
The Problem

Human resource development (HRD) research has sought to demarcate a human developmental problem by identifying learning interventions through which individuals can contribute towards group and organizational growth. However, there remains the fundamental problem, which is how to go beyond individualized employee development to a more collective resilience model building against workplace stress. Such lesser effectiveness has led to financial, emotional and psycho-social costs to individuals and collectives. Based on the theoretical analysis of human capital theory, HRD research and literature are lacking in how to more effectively operationalize collective resilience against workplace stress.

\section{The Solution}

A multi-faceted collective workforce resilience intervention conceptual model is proposed to enable both management and employees to overcome ineffective implementation of human development and thereby bounce back from workforce stress. Four aspects of the model's practical operationalization are proposed as steps to help the HRD community of practitioners and scholars to engrain resilience as a workplace culture in resolving stress.

Implications on (I) the identification of workplace stress, (2) the effective design and operationalization of development capacities. (3) the resilience intervention initiatives, and (4) the management of collective workforce resilience are highlighted.
\end{abstract}

\footnotetext{
'Lincoln International Business School, University of Lincoln, Lincoln, UK

Corresponding Author:

John Mendy, Lincoln International Business School, University of Lincoln, Lincoln, LN67TS, UK.

Email: jmendy@lincoln.ac.uk
} 


\section{The Stakeholders}

The proposed model is designed for the HRD community, including scholars, practitioners, employees and managers in related HRD contexts.

\section{Keywords}

resilience, HRD, workplace stress, collective, intervention

Although the field of HRD is multidisciplinary and has benefited from foundations in systems, psychological, and human capital theory this model building article recognizes a critical theoretical problem in terms of how human development is implemented within HRD. The problem arises from the interface between human resource management (HRM) and HRD. Both disciplines have identified the importance of human development in developing resilience capacity especially in situations causing resilience barriers (Rahman \& Mendy, 2018) not only to individuals whose learning and resilience capacity have been challenged but to entire organizations (Dormann \& Zapf, 2002; Kinman \& Grant, 2010). This theoretical problem has been highlighted by the generally accepted definition of HRD by some founding scholars including Chalofsky (1992) who defines HRD as "the study and practice of increasing the learning capacity of individuals, groups, collectives, and organizations through the development and application of learning-based interventions for the purpose of optimizing human and organizational growth and effectiveness" (p. 179).

While defining HRD as a field that develops and unleashes human potential to improve the individual, the team or group, and the organization terms of their performance, Allen et al. (2008) and Swanson (2008), notable scholars in the discipline, contend that the field has a definitional or theoretical synthesis problem. HRM, on the other hand, encompasses a more overarching systems approach which includes policies, processes, and practices within which some of HRD's practices, such as learning and talent development, are encrusted (Armstrong, 2020). Furthermore, there remains a lack of consensus of what other aspects should compose the seminal foundation of HRD and the role of the individual, group, and organization in fostering the human developmental capacity for performance (Kaufman, 2010).

In 2017, a study commissioned by the UK Prime Minister's office found that a sixth of the UK workforce (circa 32 million) were suffering from ill health, mental difficulties, and long-term absences caused by the lack of ability to bounce back from an adversity such as workplace stress (Mafabi et al., 2015). Moreover, in 2008, the Chartered Institute of Personnel and Development (CIPD), the UK's biggest and oldest HRM and HRD professional association, founded in 1913 and with over 100,000 international members, conducted a survey on why individual employees were absent from work. It was found that over thirteen million days were lost between 2007 and 2008 highlighting that the ability of individuals to be resilient was an underlying problem which has been worsened by the frequency of change and the limited organizational resources to deal with the issue (Dello Rosso \& Stoykova, 2015). 
The recent 2018 CIPD survey revealed additional, stress-associated problems including costs spiralling to twenty-nine billion pounds as a hundred and thirty days were lost per individual employee (CIPD Health and Wellbeing at Work, 2018). In the US, an exorbitant productivity loss of twenty-four billion dollars has been recorded (Forbes Report, 2013) partly as a result of individual resilience being adversely challenged thereby wreaking untold financial and productivity hardships onto companies. Other parts of the world reflect similar severity issues (Geurts \& Gründemann, 2012). Therefore, based on the previous examples given in various contexts, conceptualizing and targeting individual states of well-being (i.e., depression, anxiety, mental health, personal wellbeing) as the predominant problem by which HRD and HRM practitioners approach workplace stress and thereby engender resilience has failed. The question is what do we do about it? An alternative to the traditional proposition of learning and talent development from HRD and HRM as the basis for individual, group, and organizational development is needed (Mendy, 2019).

\section{Theoretical Perspectives on Resilience}

This urgent stress crisis has led to calls for resilience, broadly defined in the literature as the capacity of people to rejuvenate from work adversity (Defraia, 2013). Various types of resilience have been proffered including childhood resilience (the ability of children to bounce back from traumatic and less ideal family conditions of violence, poverty and drugs (Zolkoski \& Bullock, 2012) and personal resilience, especially in low and middle income countries (Bhana \& Bachoo, 2011). More recent contributions include psychological resilience, a positive psychological adaptation to adversity (Fletcher \& Sarkar, 2013); ecological resilience (the ability for ecological systems to adapt from natural hazards including hurricanes, floods and related climate change adversities (Gunderson et al., 2012); and urban resilience (the ability of urban systems to adapt to, resist or recover from major hazards (Meerow \& Newell, 2019).

Both the HRD and HRM literatures have been vocal about the benefits of the interlinkages between human development and resilience. In this regard, there have been calls to highlight the relationship between HRM systems, policies, and procedures, and the implementation of human resilience capacity building (Bardoel et al, 2014). For example, in a study of over two thousand employees in the Chinese banking sector, Cooke et al., (2019) show how high-performance work systems (HPWS) can enhance employee engagement and ultimately develop the capacity for resilience. While conceptualizing resilience as "a set of skills and attributes that can be developed through the effective use of HPWS," (p. 1254), Cooke et al opine that this perception can be beneficial to both the individual and their organization's development. On one hand, having such skills and developmental capacity to positively influence organizational outcomes (e.g., performance) has been noted in the literature (Cooper et al., 2013). On the other hand, the associated individual ability to develop resilience against barriers for greater effectiveness in performance has been sparingly examined within the context of work (Rahman \& Mendy, 2018). Considering the findings from Violanti et al (2008), the extent of the effectiveness with which measures can competently deal 
with underlying stress is questionable. In their five-year period of studying over forty policewomen and seventy policemen with depression symptoms, these researchers found that suicide prevalence became greater by $116 \%$ for increases in hours worked. Policemen who registered higher posttraumatic stress disorder (PTSD) symptoms revealed a suicide prevalence of $13 \%$ relating to the same level of work hour increase per shift. These rates are alarming despite the developmental support given to the officers.

Another emerging aspect of resilience is London's (1983) notion of career resilience, defined as "a person's resistance to career disruption in a less than optimal (i.e., adverse) environment" and the idea that such an environment may trigger "less than optimal career conditions" and "psychological fragility" (p. 621). Such resistance has been recognized by De Vos et al. (2020) who brought together empirical literature from other constructs to show how their relationships could also impact employee retention and career progression, especially in the teaching and nursing professions (see Ngoasong \& Groves, 2016).

Despite these advances in the resilience literature in HRD and HRM in general and career resilience in particular for developing such capacity (Caza \& Milton, 2012), this development is part of a trajectory including person-environmental inter-relationships and interactional fit (i.e., a process) Notably, prior and current studies have not sufficiently addressed a multiplicity of resilience building contexts which may lead to a more inclusive component definition of the term as highlighted by De Vos et al. (2020). This is partly due to the fact that the ability for humans to recover from different types of adversity is not fixed. Moreover, the practical application of HRD interventions, including learning and training, to more effectively increase the resilience of human developmental careerists remains a relatively silent issue (Kao et al., 2014). Such resilience is increasingly needed to develop resiliency in individuals, whose human development has been traumatized by fundamental psycho-social drivers of work stress, another somewhat silent topic (Youssef \& Luthans, 2007).

A range of proposals are examined in this current study, with the aim of providing an alternative, more effective approach to HRD's current individualization of human development. This conceptualization concurs with Gvaramadze's (2008) idea that HRD has developed "self-managed, autonomous, responsible, and flexible employees" (p. 474) who could potentially inadvertently heighten competition and alienation especially at a time of increasing workplace stress. Gvaramadze notes that greater individualization through employees' quest for more learning and development opportunities may be beneficial for individual growth and organizational fit, but detrimental for commitment and knowledge sharing. This polarization of the human development/human capacity theory debate has partly led to personality and emotional wellbeing adversity for a wider collective adding to the growing uncertainty of how it should be implemented in resilience building (Heyes et al., 2018). Consequently, this has led and added to less effective capacity development against stress (Chalofsky \& Cavallaro, 2013; Conz et al., 2017) individually, collectively, and organizationally. 
The research question therefore is: How can we build a practical intervention model that will help employees and managers to develop individual as well as group/collective and organizational resilience capacity in order to deal with workplace stress as an existentially complex threat? First, this research seeks to empower stakeholders in workplace stress resolution (Auer \& Cazes, 2000). Attempts to build such a model and show its operationalization are examined using resilience research propositions and examples (see next section). This research therefore contributes to resolving group and collective organizational neglect, by critiquing HRD's individualized interventions (Morris \& Madsen 2007) and developing a more holistic resilience capability approach (Kurian, 2018). Second, an intervention model is built to demonstrate this is competently accomplished (Kuchinke, 2010). Third, a new theory on Stakeholders Stress Resilience is developed as an alternative to HRD's individualization (Lock \& Janas, 2002). Fourth, theoretical insights are extended by highlighting the socio-cultural benefits that were previously overlooked (Luthans et al., 2008; Mendy, 2019).

\section{Resilience in HRD Research}

In order to build the model, a range of HRD research studies (e.g., Hezlett, 2007; Holton, 2005) that have predominantly and traditionally focused on individual properties such as learning skills and the development of the individual's capacity to perform (Bullough et al., 2014) were examined. The review of the literature uncovered areas that HRD researchers have neglected especially in terms of a more encompassing resilience building panacea (Giga et al., 2003). In particular, workplace stress is still problematic despite the recommendable financial and wellbeing benefits (Williams \& Cooper, 2002). A critical appraisal of proposals follows. Extant studies have identified two categories namely challenges or risks (i.e., stressors) and actions needed for individuals' workplace stress resolution. Stressors to human development and resilience range from organizationally/role related to job morale, work conditions (Dorman \& Zapf, 2002), job demands, lack of job control (Meier et al., 2008) to lack of emotional and social support (Büssing \& Glaser, 2000). Szatmari (2018) reported personal work-related stress issues that were overlooked in Cartwright and Cooper (1997) study that identified three stress intervention strategies: primary (minimizing stress), secondary (managing stress) and tertiary (providing support). Sharplin et al. (2011) proposed structuration, which allows work and non-work segmentation in order to reframe the individual's developmental goals. However, the required cognitive behavioral changes are not recognized in recommended stress resolution actions (Michel et al. 2014) thereby prompting a look into critical perspectives on five key models as follows.

First, using a competency model, Garmezy (1993) was one of the founding scholars who attempted to address issues related to workplace stress by investigating the way individual children dealt with extreme poverty and violence, aspects that were hampering their overall human development. Garmezy found that one set of individuals developed deficit behaviors while another set maintained a level of competence despite 
being raised in comparably difficult environments. This early focus on an individual's ability to be adaptive and to develop resilience capability (i.e., competence) when challenged was later developed in studies of positive behavior as a requisite predisposition for resilience (Masten et al., 2003).

Similarly, a Stress Management Competency Indicator Tool has been developed by the Health and Safety Executive (UK) to help individual managers and others alter their behaviours and become competent (i.e., highly development and effective) in managing the maladaptive behaviors of other employees (Yousef \& Luthans, 2007). However, the capability of the individual to bounce back from a socio-economically difficult environment (Garmezy, 1993), on the basis of their learning and educational capacity (Cicchetti, 2013) or as a result of positive competency (ter Maten-Speksnijder et al., 2012) remains debatable. This is partly because of mixed results (Meyer, 2015). While studying resilience in childhood (or human) development, Masten (2001) additionally found that focusing on developing an individual's internal system to cope with external adversity and disadvantage is critical to development of the individual. According to Masten, because holistic (i.e., organizational) resilience building provides the mundane stuff on which human adaptation and development is based, a shift from individualization to collectivization is necessary.

Second, the resource model developed by Corazon et al. (2018) emphasizes targeted and effective use of an organization's resources and structures to help individuals to develop (e.g., via HR, occupational health, counseling and guidance therapy) and become more capable (i.e., competent) of managing stress. Although psycho-social resources are thought to be useful (Luthans et al., 2007) it is not clear how this can be used for individuals' developmental benefit (Gunasekaran et al., 2011; Seville 2018). The collective aspects of learning to cope with the actual as well as perceived disadvantages caused by the adversity to human development are overlooked (Mendy \& Hack-Polay, 2018).Third, the knowledge model is built on employees' relationality (Alacovska, 2018) which in turn facilitates resilience (Conz et al., 2017). This knowledge is based on employee talent (Krishnan \& Scullion, 2017). The model is claimed to help identify individuals' learning preferences to cope with complex, difficult environments and develop self-efficacy skills for personal development (Bullough et al., 2014; Igwe et al., 2019) longer term (Auer \& Cazes, 2000). The recommended skills include human capital development, productivity, and positive emotions (Lepak \& Snell, 1999; Tugade \& Fredrickson, 2004). However, staying engaged individually has robbed the possibility of collective and organizational-level commitment and overall knowledge sharing (Gvaramadze, 2008; Luthans et al., 2007). Specifically, recognized HRD structures and processes promoting the reduction of longitudinal risk to children's growth and resilience behavior are similar to those proposed in the dynamic positioning control model. The dynamic positioning control model was applied to a study of over two thousand fixed, floating vessels using technology as a means to identify technology that eliminated risky marine operations (Sørensen, 2011). Despite such advances, the revitalization of overall organizational interactional capacity, especially for individuals 
who are left psychologically traumatized by their very organizational systems, is yet to be resolved (Luthans et al., 2008).

Fourth, the technology acceptance (or TAM) model was developed by Davis (1989) and subsequently by Davis et al. (1989) on the basis of information systems that help to ascertain the behavioral intentions and attitudes highlighting the degree to which users perceive new technologies as useful for their job performance. In so doing, the model was seen as further innovation worldwide to help tackle technological unfriendliness as a work-stressor. It is also ascertained that latest technology can help organizations and individuals be more competitive, productivity driven and anxiety-free (Colligan \& Higgins, 2006). However, additional pressures from employees' workloads and long, arduous work hours lead to person-job insecurity, a non-conducive and burnout induced work (Büssing \& Glaser, 2000; Violanti et al., 2008) and a non-value adding work environment (Mendy, 2019).

Finally, the psychological capital model (Luthans et al.,2007) reiterates the earlier Yerkes-Dodson Law (1908), which shows that when employees are psychologically inspired (i.e., feel stress) they tend to be productive. While examples from previous studies point to a positive correlation between workload pressures and ill health and lower productivity (Spector et al., 1988) others highlight a heightened individual workload, burnout and absences (Corazon et al., 2018) and even teacher and nurse depression (Violanti et al., 2008). When the job and stressors become too complex employees' mental stability suffers (Xie \& Johns, 1995) especially during organizational change events that can create uncertainty (e.g., downsizing) and risk (Cooke et al., 2019). A crucial HRM and HRD activity such as fostering individual learning and personal development fails to help (Robertson et al., 2015). Identifying and investigating the HRD activities (i.e., interventions) that can help the collective's ability to deal with a complicated and multi-layered problem are needed (Dutta \& Sobel, 2016).

\section{Resilience Model and Conceptual Development Framework}

The interdisciplinary nature of HRD is commonly acknowledged among the community of HRD scholars, practitioners, and educators. However, Chalofsky (2007) contends there is a lack of consensus on the composition of HRD's seminal disciplinary base. Chalofsky instead proposed a seminal framework of people, organizations, and learning that embodies how individual performance is enhanced through learning. Kuchinke (2010) argues for a more philosophical foundation for HRD by highlighting the lack of research and scholarly discourse on the role of morals and values in the applied field. While a values framework may be beneficial to individual development, this perspective has been shown to be less effective in collective settings and stress induced environments (Gvaramadze, 2008; Hassell et al., 2011; McVicar et al., 2013).

These foundations have been useful in determining an individual's limitations during adversity as well as the knowledge they may gain in the process. Missing however 


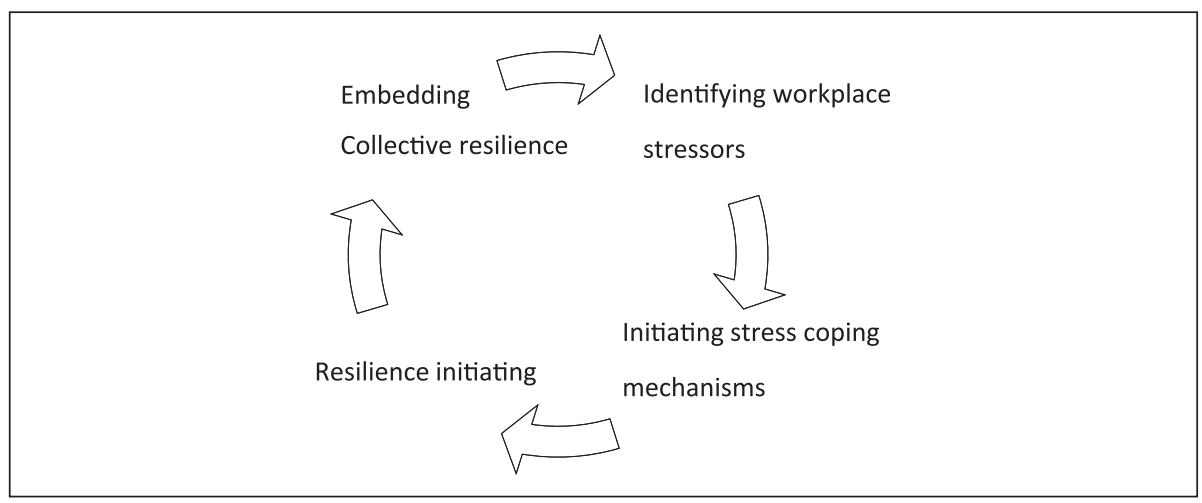

Figure I. Collective resilience intervention model.

from HRD's foundations are vital, holistic, theoretical models that explain the affective interactions between people, their learning, their organizations, and ultimately their developmental outcomes, especially in dealing with traumatic experiences like workplace stress (Robertson et al., 2015; Roelvink \& Zolkos (2015).

\section{Developing Resilience Interventions}

On the basis of the afore-analysis, a collective workforce resilience intervention model is propositioned. The model develops four capacity areas on workplace stress namely (1) identifying workplace stressors, (2) initiating resilience development, (3) combining structural and non-structural resilience, and (4) embedding collective resilience intervention. The benefits of the model include: (1) highlighting the workrelated stress, (2) initiating stress coping, (3) resilience intervention, and (4) embedding collective resilience intervention at work. Figure 1 illustrates the Collective Workforce Resilience Intervention model which consists of four areas that benefit stakeholders:

\section{Development Aspects of the Collective Resilience Intervention Model}

Resilience Intervention Development 1 is identifying the workplace stressors. This includes organizations having to encourage members to verbalize their socio-cultural preferences of what counts as stressors and therefore should be dealt with earlier (i.e., before the damage and losses to productivity creep in). Although the examples from the literature highlighted expectations (albeit with limited interventionist success) we were not significantly enlightened on how to operationalize resilience building. Part of the reasoning here is that it must be the individual employee's fault if they were not stress resilient enough. Intervention one highlights that other aspects surpassing organizational structural and procedural adherence are crucial. 
Resilience Intervention Development 2 is initiating resilience development schemes for both management and staff development. Examples from the literature showed that resilience is built onto individuals needing support, mentoring, counseling and so on. Effacing the power interplay by signaling the inclusivity of all parties was overlooked in the works of Chalofsky (2007) and Kuchinke (2010). Using structural measures (Cooper et al. 2013) that serve to alienate one group compounds the resilience and development crisis and erodes inter and intra-group cordiality and therefore resilience building at the individual, group, and organizational levels (Gvaramadze, 2008). Intervention two helps in reducing absence levels and organizational costs by dealing with the problem of collective alienation.

Resilience Intervention Development 3 recognizes how structural organizational procedures could still play in resilience building. However, material as well as nonmaterial resources (psycho-social and attitudinal) should be used within organizational, managerial, individual employee, and other stakeholder networks to combat stress. The examples from previous studies failed to spotlight on widening the conceptualization and use of HRD resources to include the non-financial, nuanced stresscombatting issues (attitudes, preferences, socio-cultural perspectives, and so on).

Resilience Intervention Development 4 is embedding collective resilience intervention into organizational structures, HRD processes and HRM systems as a way of life or an engrained responsive yet proactive approach to individualized and collectivized stressors at work. Previous studies on workplace stress have not attempted this type of approach and therefore it is claimed as novel. Intervention four specifies not only the importance of valuing stakeholder interactions but going beyond to recognize greater resilience capacity building by everyone. It no longer suffices for HRD to initiate development (Sanders et al., 2014) but to making development as part of companypractice resilience embeddedness. Beyond Roelvink and Zolkos's (2015) "affective ontologies" we should now be positively and proactively adopting resilience culture as practice.

\section{Analyzing the Collective Resilience Intervention Model}

The Collective Resilience Intervention Model fills a gap in previous studies on HRD and resilience and contributes to a wider collective of individuals (e.g., organizations') capacity to deal with workplace stress. This collective of management, staff, and other stakeholders becomes a valuable peer support for longer-term resilience and organizational effectivity/productivity. Although Bhana and Bachoo (2011) earlier attempted to show the benefits of family-(or person-related) type resilience while Gvaramadze (2008) showed the counter-productive nature of such personal developmental inducements and De Vos et al. (2020) highlighted potential personal resistance, the benefits of this to a family/collective of employees' resilience has not been attempted previously. The model's four aspects serve as intervention steps, as personal and collective resilience developmental trajectories against workplace stress. Individually, organizationally, and collectively staff and management can use the model to identify, reflect, act on and, over time, embed resilience building (see four steps). To further highlight 
the conceptual development framework that contributes to new (i.e., novel) perspectives for the advancement of theory in HRD regarding "Stakeholders" Stress Resilience' (see Table 1 below):

\section{Discussion and Implications for HRD}

The Collective Resilience Intervention model provides a different (new) way of looking into resilience, HRD interventions and workplace stress from HRD's individualized focus (see examples from previous studies (Dello Russo \& Stoykova, 2015; Gvaramadze, 2008). The model is designed to demonstrate how to more effectively deal with workplace stress at various levels. The four aspects of the model can serve as intervention strategy steps to complement the previous, lesser effective HRD structural interventions on human development. The Stakeholders' Stress Resilience was introduced as a conceptual development framework to explain the types of changes required at the three levels (i.e., the person, collective, and organization) to more effectively resolve workplace, including associated anxiety, mental difficulties, productivity loss and chronic absences.

The model offers a developmental tool that allows all stakeholders the opportunity to adapt to stress by using action-oriented approaches such as (1) identifying the source of the stress (anxiety, depression, mental difficulty and so on), (2) initiating stress coping mechanisms and skills by working as a collective to overcome the stressors, and (3) developing resilience adaptability through training, mentoring and social interactions that the individuals think will work, and (4) embedding resilience adaptability as part of a new way of doing business. The latter can be periodically evaluated by the different stakeholders using Holton's (2005) seminal Evaluation and Research Model as a framework that helps in comprehensively diagnosing and understanding the causes, influences, and outcomes of HRD interventions in order to ascertain how resilience can be maintained and sustained. Building staff capability in adversity-type environments (Puranam et al., 2014) should be complemented socio-culturally as a new way of doing business (Hofstede, 2001).

\section{Implications for HRD Theory and Practice}

The discussion in this study makes several implications. First, the Collective Resilience model highlights not only the HRM inclination towards systems but also HRD's process-specific perspective to human and organizational development. This implies that while the HRD discipline has emerged to attend to processual issues at the individual, group, and organizational levels, the findings indicate a need to recognize the overlap between HRD and HRM. Furthermore, HRD interventions such as learning and talent development, should be broadened as a strategic move, to more effectively capture and sustain resilience in each of the three levels. Thus individual learning, and the knowledge accrued thereof, is disseminated through groups and entire organizational systems in a way that mitigates against the adverse individualization as Gvaramadze (2008) highlighted. 


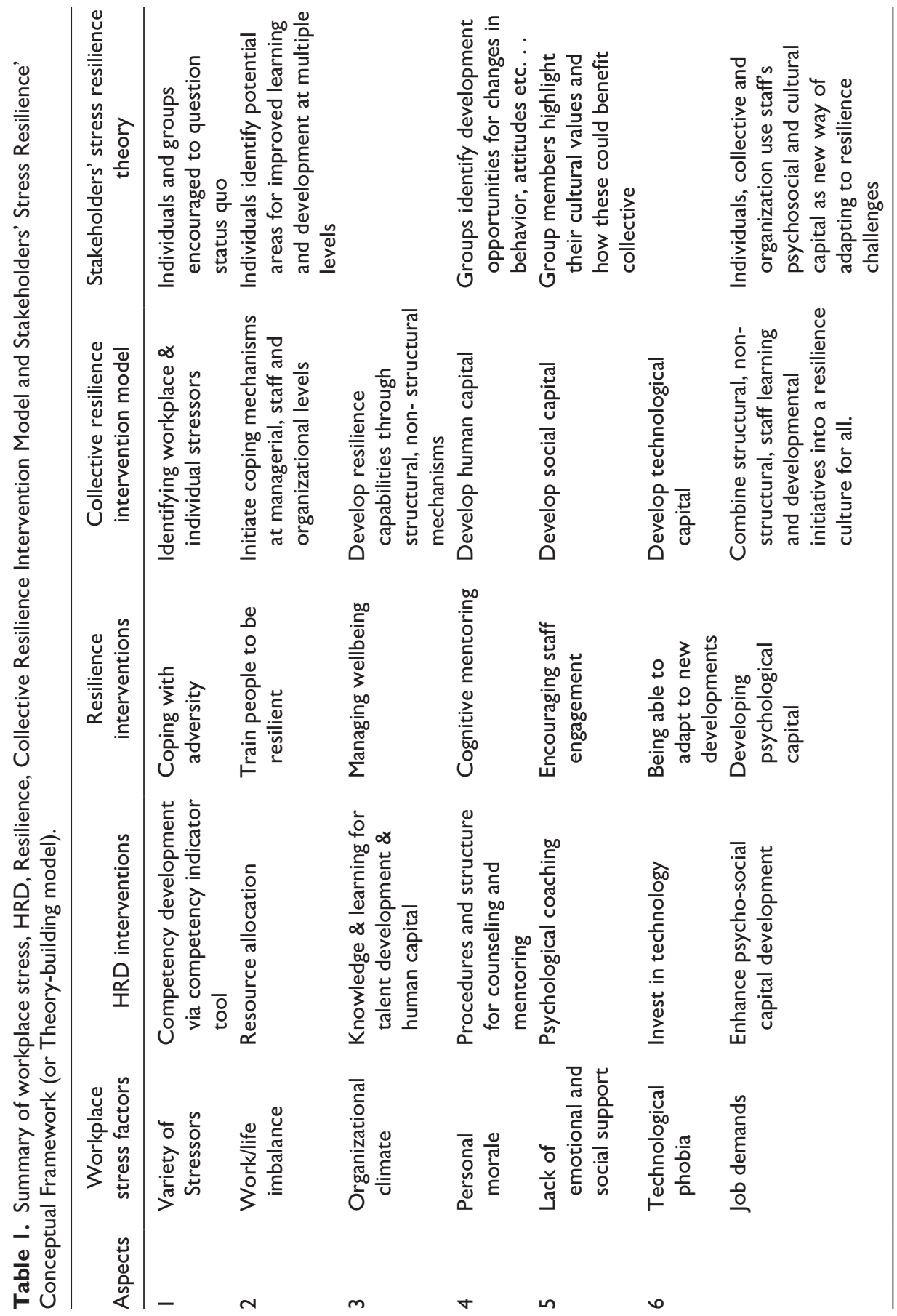


Second, an analysis of the theoretical and research foundations showed that resilience should not only be tackled at the individual level given the shortcomings highlighted but at a more systems-based (i.e., group and collective) level. In this way, the model and its four developmental characteristics could be used to introduce each of the interventions in each of the levels to help HRD practitioners intervene in resolving workplace stress (Corazon et al., 2018; Gvaramadze, 2008).

Third, in order to fill this theoretical and practical gap and thereby answer the study's research question, existing and previous models have been appraised and their lack of psycho-cultural practical application highlighted (Luthans et al., 2005). This implies that HRD needs to strengthen resilience interventions that are designed to deal with psycho-cultural constraints faced by individuals, groups, and collectives in their efforts to embed resilience building in organizational as well as HRM systems.

Fourth, HRD and resilience research could be complemented with studies that examine how an individual's psycho-cultural wellbeing, chronic absences from work, and decreased productivity negatively impact their learning and talent development as highlighted by Cicchetti (2013). HRD and HRM scholars and practitioners have sought to resolve and improve these performance related issues over the decades (Armstrong, 2020).

Fifth, practically doing so means that HRD will continue to investigate and resolve new questions and foci on not only the individual but also for the collective benefit of the HRD and HRM community of scholars and practitioners. The examples provided earlier show how secondary data could be as valuable in identifying how a theory building model on workplace stress can produce new perspectives and insights into HRD (see Table 1).

\section{Future Research}

First, future research could investigate and problematize how HRD can embed a more systems-based approach to individual, group, and organizational workplace stressrelated problems, including the application and evaluation of learning and talent development. This will facilitate both individualized and collectivized resilience analysis and research development in different workplace stress settings. Second, the conceptual development framework and Stakeholders Stress Resilience could be further investigated in a comparative analysis involving small and medium sized enterprises, multinational enterprises, and charitable companies.

\section{Conclusion}

Although resilience theory assumes that coping mechanisms are essential for stressed individuals (Seville, 2018) the predominant focus in HRD literature has been on the potential contribution of individualized learning in alleviating the adversity. The critical exploration of individualization revealed that this quality alone does not necessarily guarantee comeback (Seligman, 2011). Additionally, an exploration of individualization in terms of the HRD research methods used over the decades demonstrated that dealing 
with the longer term health implications of stress-inducements needs an alternative (or more effective) method than an over-concentrated use of case studies, personal experiences and focus groups as before (Corazon et al., 2018). This led to a collective intervention model, which was used to produce a stakeholders' stress resilience conceptual development framework to guide stakeholders to become more strategically resilient (Mendy, 2019). The model building and framework highlights an organization's structural incapacities and management's competency deficits to help the HRD community become more effective in their interventions (i.e. its currency/raison-d'etre) against the normalization of workplace stress (Heyes et al., 2018) and the individualization of human development (Gvaramadze, 2008; Mishra \& McDonald, 2020).

\section{Declaration of Conflicting Interests}

The author declared no potential conflicts of interest with respect to the research, authorship, and/or publication of this article.

\section{Funding}

The author received no financial support for the research, authorship, and/or publication of this article.

\section{References}

Alacovska, A. (2018). Informal creative labour practices: A relational work perspective. Human Relations, 71(12), 1563-1589.

Allen, W. C., Fischer, M., \& Swanson, R. A. (2008). Economics: Opportunity and challenges for human resource development. Advances in Developing Human Resources, 10(6), 882-890.

Armstrong, M., \& Taylor, S. (2020). Armstrong's handbook of human resource management practice. Kogan Page Publishers.

Auer, P., \& Cazes, S. (2000). The resilience of the long-term employment relationship: evidence from the industrialized countries. International Labour Review, 139(4), 379-408.

Bardoel, E. A., Pettit, T. M., De Cieri, H., \& McMillan, L. (2014). Employee resilience: an emerging challenge for HRM. Asia Pacific Journal of Human Resources, 52(3), 279-297.

Bhana, A., \& Bachoo, S. (2011). The determinants of family resilience among families in low and middle-income contexts: A systematic literature review. South African Journal of Psychology, 41(2), 131-139.

Bullough, A., Renko, M., \& Myatt, T. (2014). Danger zone entrepreneurs: The importance of resilience and self-efficacy for entrepreneurial intentions. Entrepreneurship Theory and Practice, 38(3), 473-499.

Büssing, A., \& Glaser, J. (2000). Four-stage process model of the core factors of burnout: The role of work stressors and work-related resources. Work and Stress, 14(4), 329-346.

Cartwright, S., \& Cooper, C. L. (1997). Managing workplace stress (Vol. 1). Sage.

Caza, B. B., \& Milton, L. P. (2012). Resilience at work: Building capability in the face of adversity. In K. S. Cameron \& G. M. Spreitzer (Eds.). The Oxford handbook of positive scholarship (pp. 895-908). Oxford University Press.

Chalofsky, N. (2007). The seminal foundation of the discipline of HRD: People, learning, and organizations. Human Resource Development Quarterly, 18(3), 431-442. 
Chalofsky, N., \& Cavallaro, L. (2013). A good living versus a good life: Meaning, purpose, and HRD. Advances in Developing Human Resources, 15(4), 331-340.

Chartered Institute of Personnel and Development. (2008). Absence Management Survey Report (2007 - 2008).

Chartered Institute of Personnel and Development. (2018). Annual Survey Report (2018).

Cicchetti, D. (2013). Annual research review: Resilient functioning in maltreated children past, present, and future perspectives. Journal of Child Psychology and Psychiatry, 54(4), 402-422.

Colligan, T. W., \& Higgins, E. M. (2006). Workplace stress etiology and consequences. Journal of Workplace Behavioral Health, 21(2), 89-97.

Conz, E., Denicolai, S., \& Zucchella, A. (2017). The resilience strategies of SMEs in mature clusters. Journal of Enterprising Communities: People and Places in the Global Economy, 11(1), 186-210.

Cooke, F. L., Cooper, B., Bartram, T., Wang, J., \& Mei, H. (2019). Mapping the relationships between high-performance work systems, employee resilience and engagement: A study of the banking industry in China. The International Journal of Human Resource Management, 30(8), 1239-1260.

Cooper, C., Flint-Taylor, J., \& Pearn, M. (2013). Building resilience for success: A resource for managers and organizations. Palgrave Macmillan.

Corazon, S., Nyed, P., Sidenius, U., Poulsen, D., \& Stigsdotter, U. (2018). A long-term follow up of the efficacy of nature-based therapy for adults suffering from stress-related illnesses on levels of healthcare consumption and sick-leave absence: A randomized controlled trial. International Journal of Environmental Research and Public Health, 15(1), 137.

Davis, F. D. (1989). Perceived usefulness, perceived ease of use, and user acceptance of information technology. MIS Quarterly, 319-340.

Davis, F. D., Bagozzi, R. P., \& Warshaw, P. R. (1989). User acceptance of computer technology: a comparison of two theoretical models. Management science, 35(8), 982-1003.

Defraia, G. S. (2013). Organizational outcomes following traumatic workplace incidents: A practice-based exploration of impact of incident severity level. Social Work in Mental Health, 11(5), 404-433.

Dello Russo, S., \& Stoykova, P. (2015). Psychological capital intervention (PCI): A replication and extension. Human Resource Development Quarterly, 26(3), 329-347.

De Vos, A., Van der Heijden, B. I., \& Akkermans, J. (2020). Sustainable careers: Towards a conceptual model. Journal of Vocational Behavior, 117, 103196.

Dormann, C., \& Zapf, D. (2002). Social stressors at work, irritation, and depressive symptoms: Accounting for unmeasured third variables in a multi-wave study. Journal of Occupational and Organizational Psychology, 75(1), 33-58.

Dutta, N., \& Sobel, R. (2016). Does corruption ever help entrepreneurship? Small Business Economics, 47(1), 179-199.

Fletcher, D., \& Sarkar, M. (2013). Psychological resilience: A review and critique of definitions, concepts, and theory. European psychologist, 18(1), 12.

Forbes Report. (2013). The causes and costs of absenteeism in the workplace. Investopedia, July 10, 2013. https://www.forbes.com/sites/investopedia/2013/07/10/the-causes-and-costs-ofabsenteeism-in-the-workplace/\#4ab7eb353eb6

Garmezy, N. (1993). Children in poverty: Resilience despite risk. Psychiatry, 56(1), 127-136.

Giga, S. I., Cooper, C. L., \& Faragher, B. (2003). The development of a framework for a comprehensive approach to stress management interventions at work. International Journal of Stress Management, 10(4), 280. 
Geurts, S., \& Gründemann, R. (2012). Workplace stress and stress prevention in Europe. In M. A. J. Kompier \& C. Cooper (Eds.) Preventing stress, improving productivity. (pp. 27-50). Routledge.

Gunasekaran, A. B., Rai, K., \& Griffin, M. (2011). Resilience and competitiveness of small and medium size enterprises: An empirical research. International Journal of Production Research, 49(18), 5489-5509.

Gunderson, L. H., Allen, C. R., \& Holling, C. S. (Eds.) (2012). Foundations of ecological resilience. Island Press.

Gvaramadze, I. (2008). Human resource development practice: The paradox of empowerment and individualization. Human Resource Development International, 11(5), 465-477.

Hassell, K. D., Archbold, C. A., \& Stichman, A. J. (2011). Comparing the workplace experiences of male and female police officers: Examining workplace problems, stress, job satisfaction and consideration of career change. International Journal of Police Science and Management, 13(1), 37-53.

Heyes, J., Moore, S., Newsome, K., \& Tomlinson, M. (2018). Living with uncertain work. Industrial Relations Journal, 49(5-6), 420-437.

Hezlett, S. A., \& Gibson, S. K. (2007). Linking mentoring and social capital: Implications for career and organization development. Advances in Developing Human Resources, 9(3), 384-411.

Hofstede, G. (2001). Cultures Consequences: comparing values, behaviours, institutions and organisations across nations. California: Thousand Oaks.

Holton III, E. F. (2005). Holton's evaluation model: New evidence and construct elaborations. Advances in Developing Human Resources, 7(1), 37-54.

Igwe, P. A., Hack-Polay, D., Mendy, J., Fuller, T., \& Lock, D. (2019). Improving higher education standards through reengineering in West African universities-A case study of Nigeria. Studies in Higher Education, 1-14.

Kao, K. Y., Rogers, A., Spitzmueller, C., Lin, M. T., \& Lin, C. H. (2014). Who should serve as my mentor? The effects of mentor's gender and supervisory status on resilience in mentoring relationships. Journal of Vocational Behavior, 85(2), 191-203.

Kaufman, B. E. (2010). The theoretical foundation of industrial relations and its implications for labor economics and human resource management. ILR Review, 64(1), 74-108.

Kinman, G., \& Grant, L. (2010). Exploring stress resilience in trainee social workers: The role of emotional and social competencies. The British Journal of Social Work, 41(2), 261-275.

Krishnan, T. N., \& Scullion, H. (2017). Talent management and dynamic view of talent in small and medium enterprises. Human Resource Management Review, 27(3), 431-441.

Kuchinke, K. P. (2010). Human development as a central goal for human resource development. Human Resource Development International, 13(5), 575-585.

Kurian, D. (2018). Organizational justice: Why does it matter for HRD. Journal of Organizational Psychology, 18(2), 11-22.

Lepak, D. P., \& Snell, S. A. (1999). The human resource architecture: Toward a theory of human capital allocation and development. Academy of Management Review, 24(1), 31-48.

Lock, R. H., \& Janas, M. (2002). Build resiliency. Intervention in School and Clinic, 38(2), 117121.

London, M. (1983). Toward a theory of career motivation. Academy of Management Review, $8(4), 620-630$.

Luthans, F., Avolio, B. J., Walumbwa, F. O., \& Li, W. (2005). The psychological capital of Chinese workers: Exploring the relationship with performance. Management and Organization Review, 1(2), 249-271. 
Luthans, F., Avolio, B. J., Avey, J. B., \& Norman, S. M. (2007). Positive psychological capital: Measurement and relationship with performance and satisfaction. Personnel Psychology, $60(3), 541-572$.

Luthans, F., Avey, J. B., \& Patera, J. L. (2008). Experimental analysis of a web-based training intervention to develop positive psychological capital. Academy of Management Learning and Education, 7(2), 209-221.

Mafabi, S., Munene, S. M., \& Ahiauzu, A. (2015). Creative climate and organisational resilience: the mediating role of innovation. International Journal of Organizational Analysis, 23(4), 564-587.

Meerow, S., \& Newell, J. P. (2019). Urban resilience for whom, what, when, where, and why? Urban Geography, 40(3), 309-329.

Masten, A. S. (2001). Ordinary magic: Resilience processes in development. American Psychologist, 56(3), 227.

Masten, A. S., Powell, J. L., \& Luthar, S. S. (2003). A resilience framework for research, policy, and practice. Resilience and vulnerability: Adaptation in the context of childhood adversities, 1(25), 153.

McVicar, A., Munn-Giddings, C., \& Seebohm, P. (2013). Workplace stress interventions using participatory action research designs. International Journal of Workplace Health Management, 6(1), 18-37.

Meier, L. L., Semmer, N. K., Elfering, A., \& Jacobshagen, N. (2008). The double meaning of control: Three-way interactions between internal resources, job control, and stressors at work. Journal of Occupational Health Psychology, 13(3), 244.

Mendy, J. (2019). Supporting creating shared value: including local and global clusters of staff resistance to strategic SME restructuring. Strategic Change, 28(2), 157-161.

Mendy, J., \& Hack-Polay, D. (2018). Learning from failure: A study of failed enterprises of self employed African migrants in the UK. Journal of Small Business and Enterprise Development, 25(2), 330-343.

Meyer, I. H. (2015). Resilience in the study of minority stress and health of sexual and gender minorities. Psychology of Sexual Orientation and Gender Diversity, 2(3), 209.

Michel, A., Bosch, C., \& Rexroth, M. (2014). Mindfulness as a cognitive-emotional segmentation strategy: An intervention promoting work-life balance. Journal of Occupational and Organizational Psychology, 87(4), 733-754.

Morris, M. L., \& Madsen, S. R. (2007). Advancing work-Life integration in individuals, organizations, and communities. Advances in Developing Human Resources, 9(4), 439-454.

Ngoasong, M. Z., \& Groves, W. N. (2016). Determinants of personal resilience in the workplace: nurse prescribing in an African work context. Human Resource Development International, 19(3), 229-244.

Puranam, P., Alexy, O., \& Reitzig, M. (2014). What's "new" about new forms of organizing? Academy of Management Review, 39(2), 162-180.

Rahman, M., \& Mendy, J. (2018). Evaluating people-related resilience and non-resilience barriers of SMEs' internationalisation: A developing country perspective. International Journal of Organisational Analysis, 27(2), 225-240.

Robertson, I. T., Cooper, C. L., Sarkar, M., \& Curran, T. (2015). Resilience training in the workplace from 2003 to 2014: A systematic review. Journal of Occupational and Organizational Psychology, 88(3), 533-562.

Roelvink, G., \& Zolkos, M. (2015). Affective ontologies: Post-humanist perspectives on the self, feeling and inter-subjectivity. Emotion, Space and Society, 14, 47-49. 
Sanders, M. R., Kirby, J. N., Tellegen, C. L., \& Day, J. J. (2014). The Triple P-Positive Parenting Program: A systematic review and meta-analysis of a multi-level system of parenting support. Clinical Psychology Review, 34(4), 337-357.

Seligman, M. E. (2011). Building resilience. Harvard Business Review, 89(4), 100-106.

Seville, E. (2018). Building resilience: How to have a positive impact at the organizational and individual employee level. Development and Learning in Organizations: An International Journal, 32(3), 15-18.

Sharplin, E., O’Neill, M., \& Chapman, A. (2011). Coping strategies for adaptation to new teacher appointments: Intervention for retention. Teaching and Teacher Education, 27(1), $136-146$.

Sørensen, A. J. (2011). A survey of dynamic positioning control systems. Annual Reviews in Control, 35(1), 123-136.

Spector, P. E., Dwyer, D. J., \& Jex, S. M. (1988). Relation of job stressors to affective, health, and performance outcomes: A comparison of multiple data sources. Journal of Applied Psychology, 73, 11-19.

Swanson, R. A. (2008). Economic foundation of human resource development: Advancing the theory and practice of the discipline. Advances in Developing Human Resources, 10(6), 763-769.

Szatmari, P. (2018). Risk and resilience in autism spectrum disorder: A missed translational opportunity? Developmental Medicine and Child Neurology, 60, 225-229.

ter Maten-Speksnijder, A. J., Grypdonck, M. H., Pool, A., \& Streumer, J. N. (2012). Learning opportunities in case studies for becoming a reflective nurse practitioner. Journal of Nursing Education, 51(10), 563-569.

Tugade, M. M., \& Fredrickson, B. L. (2004). Resilient individuals use positive emotions to bounce back from negative emotional experiences. Journal of Personality and Social Psychology, 86(2), 320.

Violanti, J. M., Paton, D. P., Johnston, K., Burke, J., Clarke, J., \& Keenan, D. (2008). Stress shield: A model of police resiliency. Emergency Mental Health, 10(2), 95-108.

Williams, S., \& Cooper, L. (2002). Managing workplace stress. Chichester: Wiley.

Xie, J. L., \& Johns, G. (1995). Job scope and stress: Can scope be too high? Academy of Management Journal, 38, 128-1309.

Yerkes, R. M., \& Dodson, J. D. (1908). The relation of strength of stimulus to rapidity of habit formation. Journal of Comparative Neurological Psychology, 18, 459-482.

Youssef, C. M., \& Luthans, F. (2007). Positive organizational behavior in the workplace: The impact of hope, optimism, and resilience. Journal of Management, 33(5), 774-800.

Zolkoski, S. M., \& Bullock, L. M. (2012). Resilience in children and youth: A review. Children and Youth Services Review, 34(12), 2295-2303.

\section{Author Biography}

John Mendy is the research lead for HRM at the Autism Research and Innovation Centre and a Senior Lecturer at Lincoln International Business School, University of Lincoln, UK. He is a UK HEA Fellow and Chartered CIPD and has written and published research on methodology, teaching and learning, resilience, organizational change, strategy and internationlization among other things in peer reviewed journals. 